\title{
Synthesis and Antiproliferative and Metabolic Evaluations of Novel Securinine Derivatives
}

\author{
Marc Perez, ${ }^{\dagger}$ Tahar Ayad, ${ }^{\dagger}$ Philippe Maillos, ${ }^{\ddagger}$ Valérie Poughon, ${ }^{\S}$ Jacques Fahy, $^{*}$, \\ and Virginie Ratovelomanana-Vidal ${ }^{*}, \dagger$ \\ ${ }^{\dagger}$ PSL Research University, Chimie ParisTech - CNRS, Institut de Recherche de Chimie Paris, 75005 Paris, France \\ ${ }^{\ddagger}$ Institut de Recherche Pierre Fabre, 81600 Gaillac, France \\ ${ }^{\S}$ Unité de Service et de Recherche CNRS-Pierre Fabre n ${ }^{\circ} 3388$ ETaC CRDPF, 31035 Toulouse, France
}

\section{Supporting Information}

\begin{abstract}
New securinine analogues have been prepared by semisynthesis. Two series were developed using either Suzuki or Sonogashira cross coupling reactions. The in vitro cytotoxicity of the compounds was assayed against HCT-116 colon cancer cells. The most potent derivatives showed promising growth inhibition on four tumoral cell lines giving a valuable insight on the structure-activity relationship (SAR) of securinine. Moreover, high antiproliferative effect against A-
\end{abstract}

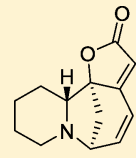

Securinine

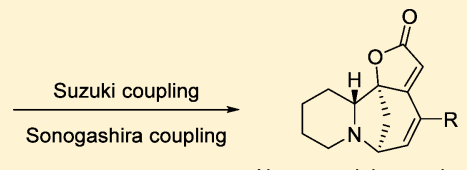

New securinine analogues $\mathrm{R}=$ aryl, alkynyl

$\mathrm{IC}_{50}=60 \mathrm{nM}$ against $\mathrm{A} 375$ cancer cell line

KEYWORDS: Securinine, semisynthesis, cytotoxicity

$\mathrm{I}^{\mathrm{n}}$ $\mathrm{n}$ the course of our exploratory medicinal chemistry program, 1 we were interested in identifying natural products as starting materials for the synthesis of new derivatives with potent biological activities. From an optimal point of view, we determined that the prospective products should be available in sufficient quantities so as to allow chemists to perform numerous assays, should include a "reasonable level" of drug likeness, should not be currently extensively used for such purposes, and should preferably exhibit, although not necessarily, biological activity. Securinine (1), a member of the alkaloid family that appeared to offer all the above characteristics, was consequently selected as the starting point substrate (Figure 1).

Compound $\mathbf{1}$ is an alkaloid isolated from the roots and leaves of the shrub, Securinega suffruticosa, which is naturally occurring in Russia and Asia, where it is used in traditional Chinese medicine. ${ }^{1-3}$ For example, 1 was used as a medication in Russia and China and showed to exert beneficial effects on diseases such as amyotrophic lateral sclerosis and poliomyelitis. ${ }^{4,5}$ Subsequently, 1 was characterized as a $\mathrm{GABA}_{\mathrm{A}}$ receptor antagonist. ${ }^{6,7}$ More recently, several publications relating the pharmacological properties of $\mathbf{1}$ in the anticancer domain appeared in the literature. ${ }^{8,9}$ Specifically, in 2010, Wald et al. have demonstrated that $\mathbf{1}$ inhibited the growth of colon cancer cells (HCT-116). ${ }^{10}$ This cytotoxic activity is suggested to proceed through the

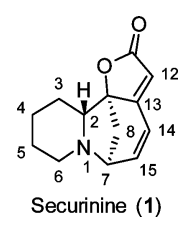

Figure 1. Structure of securinine.
Scheme 1. Synthesis of 14-Iodosecurinine 2a

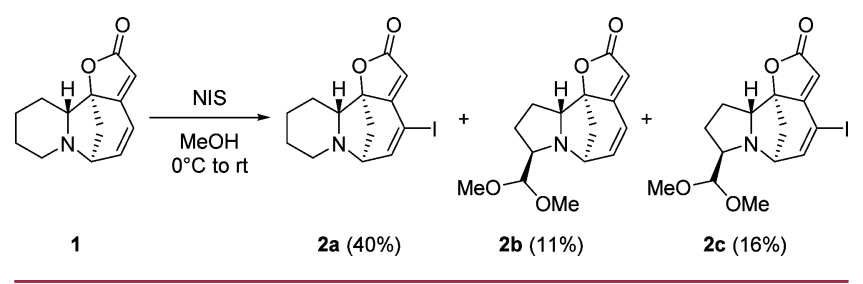

Scheme 2. Synthesis of Derivatives 3a-3l

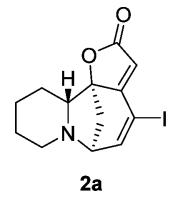

2a

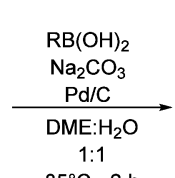

$85^{\circ} \mathrm{C}-2 \mathrm{~h}$

3a $\mathrm{R}=\mathrm{C}_{6} \mathrm{H}_{5}, 86 \%$

3b $\mathrm{R}=m \mathrm{Me}-\mathrm{C}_{6} \mathrm{H}_{4}, 50 \%$ 3c $\mathrm{R}=p \mathrm{Me}-\mathrm{C}_{6} \mathrm{H}_{4}, 83 \%$ 3d R $=p t \mathrm{Bu}-\mathrm{C}_{6} \mathrm{H}_{4}, 89 \%$ 3e $\mathrm{R}=p \mathrm{~N}\left(\mathrm{CH}_{3}\right)_{2}-\mathrm{C}_{6} \mathrm{H}_{4}, 87 \%$ 3f $\mathrm{R}=p \mathrm{Ph}-\mathrm{C}_{6} \mathrm{H}_{4}, 72 \%$

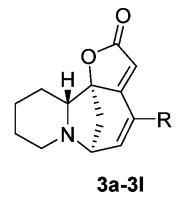

3g R $=p \mathrm{CF}_{3}-\mathrm{C}_{6} \mathrm{H}_{4}, 93 \%$ $3 \mathrm{~h} \mathrm{R}=p \mathrm{~F}-\mathrm{C}_{6} \mathrm{H}_{4}, 84 \%$ 3i $\mathrm{R}=p \mathrm{Br}-\mathrm{C}_{6} \mathrm{H}_{4}, 84 \%$ 3j $\mathrm{R}=p \mathrm{CHO}-\mathrm{C}_{6} \mathrm{H}_{4}, 77 \%$ 3k R $=p \mathrm{CO}_{2} \mathrm{Me}_{-} \mathrm{C}_{6} \mathrm{H}_{4}, 72 \%$ 3I $\mathrm{R}=2$-furyl, $25 \%$ modulation of the protein p73 expression. One year later, the same team confirmed the activity of 1 on various cancer cell lines including HL-60 (leukemia), OCI-AML3 (leukemia), and THP1 (leukemia). A significant growth inhibition in an in vivo model of acute myeloid leukemia (HL-60) in nude mice was also highlighted through a differentiating effect. ${ }^{11-13}$ Finally, $\mathbf{1}$ has

Received: November 17, 2015

Accepted: February 2, 2016

Published: February 2, 2016 
Table 1. Cytotoxic Activity of 3a-31 on Colon Cancer Cell Line HCT-116

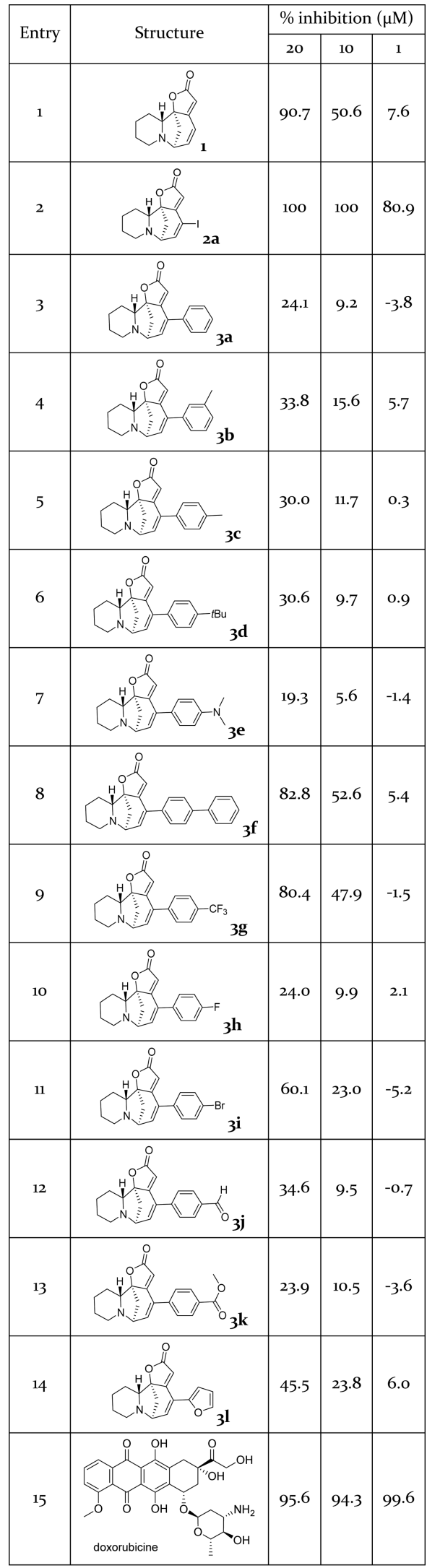

been identified as a covalent inhibitor of protein disulfide isomerase (PDI), a molecular chaperone that catalyzes disulfide
Scheme 3. Synthesis of Derivatives $4 a-4 w$

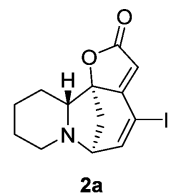

4a $\mathrm{R}=n \mathrm{Bu}, 98 \%$ 4b R $=n$ Pent, $90 \%$ $4 \mathrm{c} R=t \mathrm{Bu}, 81 \%$ 4d R $=\mathrm{cPr}, 98 \%$ 4e $\mathrm{R}=\mathrm{cHex}, 89 \%$ 4f $\mathrm{R}=$ cHex-1ene, $99 \%$ $4 \mathrm{~g} \mathrm{R}=\mathrm{SiMe}_{3}, 83 \%$ 4h R $=\mathrm{CH}_{2} \mathrm{NHBoc}, 94 \%$

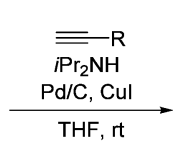

$4 \mathrm{R}=\left(\mathrm{CH}_{2}\right)_{3} \mathrm{NHBoc}, 78 \% \quad 4 \mathrm{q} \mathrm{R}=p \mathrm{Me}-\mathrm{C}_{6} \mathrm{H}_{4}, 96 \%$ 4j R = cHex-4-NHBoc, 82\% 4r R = pOMe- $\mathrm{C}_{6} \mathrm{H}_{4}, 76 \%$ 4k R $=\mathrm{CH}_{2} \mathrm{OH}, 63 \% \quad$ 4s R $=p \mathrm{~N}\left(\mathrm{CH}_{3}\right)_{2}-\mathrm{C}_{6} \mathrm{H}_{4}, 97 \%$ $4 \mathrm{I} \mathrm{R}=\mathrm{CH}\left(\mathrm{CH}_{3}\right)_{2} \mathrm{OH}, 92 \% \quad 4 \mathrm{t} \mathrm{R}=p \mathrm{~N}\left(\mathrm{C}_{2} \mathrm{H}_{5}\right)_{2}-\mathrm{C}_{6} \mathrm{H}_{4}, 97 \%$ $4 \mathrm{~m} \mathrm{R}=\left(\mathrm{CH}_{2}\right)_{3} \mathrm{OH}, 86 \% \quad 4 \mathrm{u} \mathrm{R}=p \mathrm{~N}\left(\mathrm{CH}_{2}\right)_{5}-\mathrm{C}_{6} \mathrm{H}_{4}, 97 \%$ $4 \mathrm{n}=\left(\mathrm{CH}_{2}\right)_{3} \mathrm{Cl}, 91 \%$ $40 \mathrm{R}=\mathrm{C}_{6} \mathrm{H}_{5}, 92 \%$ $4 p \mathrm{R}=0 \mathrm{CF}_{3}-\mathrm{C}_{6} \mathrm{H}_{4}, 79 \%$ $4 \mathrm{v}=p \mathrm{~F}-\mathrm{C}_{6} \mathrm{H}_{4}, 93 \%$ 4w R = 3-pyridyl, $48 \%$

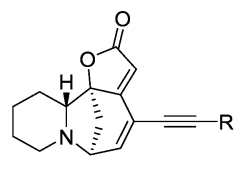

$4 a-4 w$

bond formation and reduction, which has been proposed as a target for cancer therapy. ${ }^{14,15}$ Considering the potential activity of $\mathbf{1}$ as an anticancer treatment, we became interested in its use as a precursor for the synthesis of novel compounds. Here, we report the synthesis and the preliminary biological evaluation of two original series of securinine derivatives.

The synthesis begins with the preparation of 14-iodosecurinine (2a) according to the procedure reported by Wang and Chen. ${ }^{16}$ Compound 1 reacts with $\mathrm{N}$-iodosuccinimide in methanol at $0{ }^{\circ} \mathrm{C}$ to give a mixture of products, of which $2 \mathrm{a}$ can be isolated in $40 \%$ yield. Two secondary compounds, which are a ring contraction product $\mathbf{2 b}$ and its iodinated analogue $\mathbf{2 c}$, have been isolated in $11 \%$ and $16 \%$ yields, respectively (Scheme $1)$.

The first series was obtained by Suzuki coupling from $2 \mathbf{a}$ and commercial boronic acids to yield the desired compounds $\mathbf{3 a}-\mathbf{3 l}$ (Scheme 2). Using $1 \mathrm{~mol} \%$ of palladium on active carbon as the catalyst, sodium carbonate as the base, in a 1:1 mixture of water and 1,2-DME, we were able to efficiently couple diverse boronic acids to give the resulting derivatives $\mathbf{3 a}-\mathbf{3 l}$ with yields ranging from $25 \%$ to $93 \%$.

For instance, $m$-tolyl and $p$-tolyl boronic acids were coupled with $50 \%$ and $83 \%$ yields, respectively $(3 b-3 c)$. Unfortunately, $o$-tolyl boronic acid did not react using our experimental conditions. The presence of a bulky tert-butyl group on the phenyl ring was well tolerated affording the product 3d in $89 \%$ yield. The use of an amine substituted benzene boronic acid gave the coupling product $3 \mathbf{e}$ in $87 \%$ yield. In order to assess a steric effect, 4-phenyl benzene boronic acid was engaged in our conditions to afford the biphenyl compound $3 f$ with $72 \%$ yield. Substituents such as electron withdrawing halogens provided the desired products $3 \mathbf{h}$ and $3 \mathbf{i}$ in $84 \%$ yields. Interestingly, $3 \mathbf{i}$ offers an additional chemical handle for further functionalization. Other electron withdrawing groups such as aldehyde and ester were also well tolerated affording the expected compounds $3 \mathbf{j}$ and $3 \mathbf{k}$ with respectively $77 \%$ and $72 \%$ yield. Finally, 2 -furyl boronic acid was coupled in $25 \%$ yield.

This set of compounds was evaluated for its in vitro cytotoxic properties against the human colon cancer cell line HCT-116 at concentrations of 20,10 , and $1 \mu \mathrm{M}$. Growth inhibition was measured after a $72 \mathrm{~h}$ exposure to the compound. Results of these experiments are reported as percentage of growth inhibition compared to nontreated cells in the following table (Table 1). Under our experimental conditions, securinine 1 was found weakly active, inducing only approximately 50\% growth inhibition at $10 \mu \mathrm{M}$. This value is in agreement with the previously reported data in which $\mathrm{IC}_{50}$ on two cell lines (A549 and MCF-7) is around $25 \mu \mathrm{M}^{8,9}$ 
Table 2. Cytotoxic Activity of Derivatives 4a-4w on Colon Cancer Cell Line HCT-116

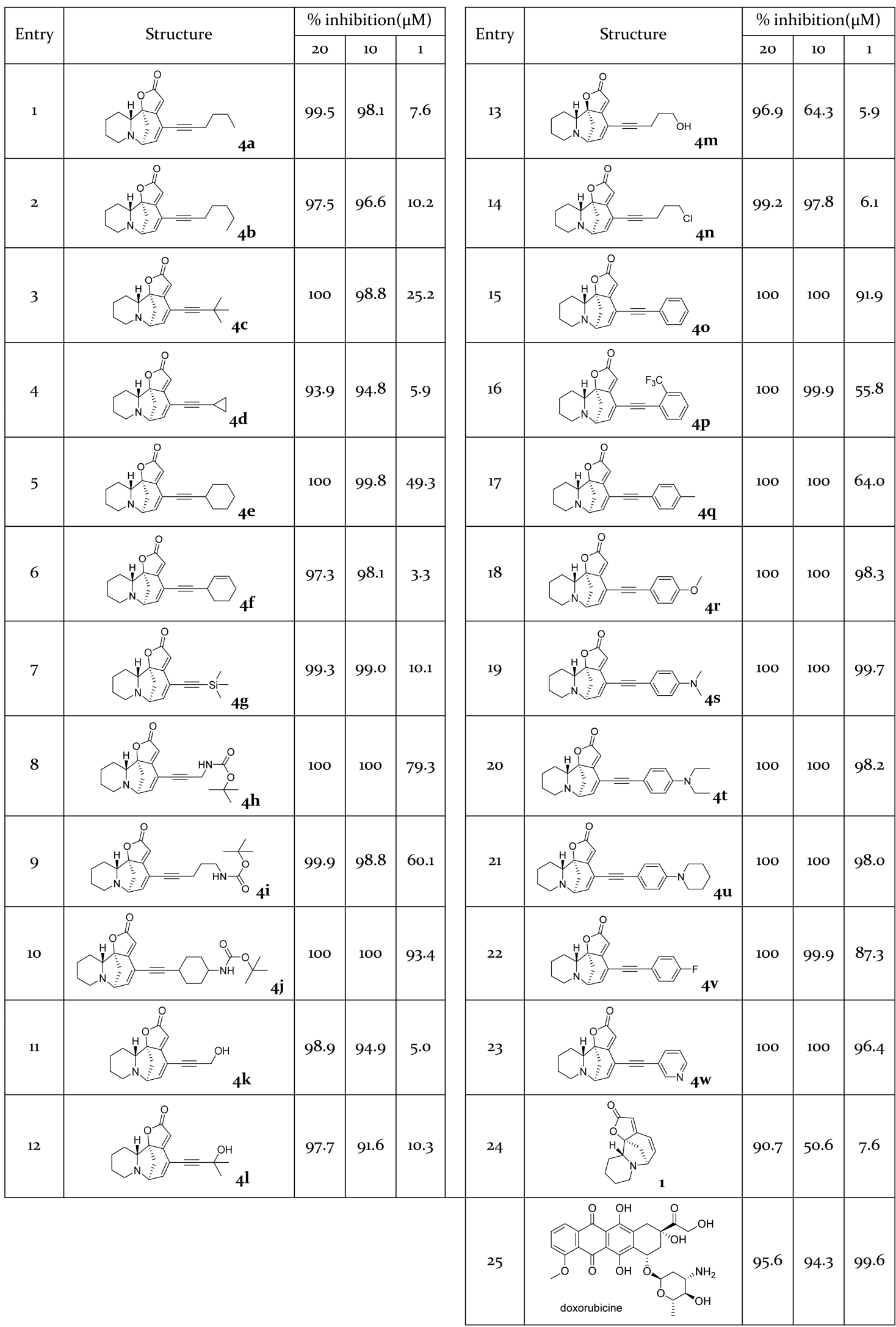

The results obtained with 14-iodosecurinine 2 a showed an increase in potency with a growth inhibition of $80 \%$ at $1 \mu \mathrm{M}$, thus suggesting that diversification at the $\mathrm{C}_{14}$ position might lead to more potent derivatives of securinine. Disappointingly, this assessment was partially rejected as most of the derivatives proved to be poorly cytotoxic. Indeed, only $\mathbf{3 f}$ and $\mathbf{3 g}$ were found 
Table 3. Antiproliferative Activities Evaluated on Four Cell Lines: A-375 (Melanoma), A549 (Lung), HCT-116 (Colon), and HL-60 (Leukemia) ${ }^{a}$

\begin{tabular}{lllll} 
& \multicolumn{4}{c}{ Cytotoxicity $($ IC50, $\mu \mathrm{M})$} \\
\cline { 2 - 5 } camptothecin & A-375 & A549 & HCT-116 & HL-60 \\
etoposide & 0.013 & 0.009 & 0.003 & 0.035 \\
securinine 1 & 0.24 & 0.59 & $>10$ & 0.86 \\
$\mathbf{4 h}$ & 6.1 & $>10$ & $>10$ & $>10$ \\
$\mathbf{4 q}$ & 0.36 & 2.64 & 1.66 & 5.00 \\
$\mathbf{4 v}$ & 1.75 & $>10$ & n. t. & $>10$ \\
$\mathbf{4 s}$ & 2.82 & 3.99 & 2.47 & $>10$ \\
$\mathbf{4 r}$ & 0.17 & 0.60 & 0.42 & 0.42 \\
$\mathbf{4 w}$ & 0.06 & 0.29 & 0.34 & 0.66 \\
$\boldsymbol{a}_{\text {n.t.: } \text { not tested. }}$ & 0.95 & 4.4 & n.t. & $>10$ \\
\hline
\end{tabular}

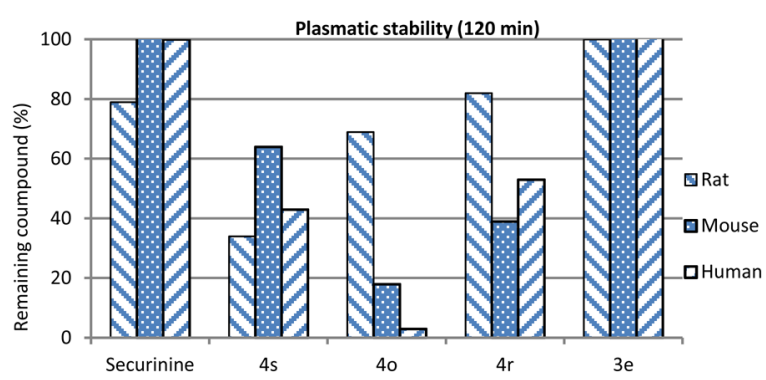

Figure 2. Plasmatic stability: percentage of parent compounds left after 120 min incubation at $37^{\circ} \mathrm{C}$ in plasma (rat, mouse, and human).

to be weakly active with growth inhibition comparable to that of 1. Such results lead us to consider that a spacer between the securinine scaffold and its appendage might be necessary to afford more potent derivatives. Based on this consideration, we envisioned the synthesis of compounds bearing an alkyne moiety as spacer.

The second series was synthesized through Sonogashira coupling between $2 \mathrm{a}$ and a set of commercial terminal acetylene derivatives to yield the corresponding alkynes $\mathbf{4 a - 4 w}$ (Scheme 3). ${ }^{17-19}$ The reaction was run in THF at room temperature using $\mathrm{N}, \mathrm{N}$-diisopropylamine with a catalytic amount of copper iodide and palladium source. Again, the use of palladium on activated carbon proved to be very convenient. ${ }^{20}$

The resulting alkyne derivatives $\mathbf{4 a - 4 w}$ were isolated after silica gel column chromatography with yields ranging from $48 \%$ to $99 \%$. Products bearing a branched or linear alkyl moiety such as $n$-butyl or tert-butyl were obtained with yields up to $98 \%$ (4a and $4 c$ ). The presence of a cyclic substituent attached to the alkyne moiety gave similar results with yields comprised between $82 \%$ and $99 \%(4 \mathbf{d}-\mathbf{f}$ and $4 \mathbf{j})$. The presence of heteroatoms on the alkyne partner was also investigated. Most of the coupling products were obtained with good yields spanning from $63 \%$ to 94\% $(\mathbf{4 g}-\mathbf{n})$. N-Boc-propargylamine (4h) was obtained with an excellent yield of $94 \%$. Gratifyingly, phenylacetylene and its derivatives reacted with 14-iodosecurinine $2 \mathrm{a}$ to give the corresponding alkynes with high yields (4o-v, $76 \%$ to $96 \%)$. The presence of an electron withdrawing or electron donating group did not seem to influence the course of the reaction ( $4 p-$ v). Finally, the coupling of 3-ethynylpyridine afforded $4 w$ in $48 \%$ yield.

With compounds $\mathbf{4 a - 4 w}$ in hand, we then evaluated their in vitro cytotoxic properties against the human colon cancer cell line HCT-116 at concentrations of 20,10 , and $1 \mu \mathrm{M}$. Growth inhibition was measured after a $72 \mathrm{~h}$ exposure to the compound, results are reported in Table 2 as percentage of growth inhibition compared to nontreated cells. It appears clearly that the introduction of a phenyl group (compounds 40 to $4 \mathbf{v}$ ) induced a dramatic increase in potency, as shown by growth inhibition superior to $50 \%$ even at $1 \mu \mathrm{M}$. Derivatives bearing aliphatic substituents, such as $\mathbf{4 a}-\mathbf{d}$, were also more potent than $\mathbf{1}$ but to a lesser extent. The cyclohexyl derivative $4 \mathbf{e}$ was found to be the most potent among the aliphatic series, comparable to the substituted phenyl series $\mathbf{4 o - v}$. These results indicate that lipophilic bulky substituents seem to be favorable for increasing the cytotoxic properties. The carbamate derivative $4 \mathrm{~h}$ exhibited a cytotoxic potency as high as that of the compounds $40-\mathbf{w}$, consequently offering an additional and attractive possibility to design a new subseries of active compounds.

Subsequently a set of the most active derivatives from Table 2, inducing more than $60 \%$ proliferation inhibition at $1 \mu \mathrm{M}$, was selected for further experiments to characterize more precisely their cytotoxic properties by determining their $\mathrm{IC}_{50}$ on four different human cancer cell lines. It should be noted that camptothecin and etoposide, two widely used topoisomerase I and II inhibitors, respectively, from natural origin were selected as reference compounds. Under our experimental conditions, compounds exhibiting $\mathrm{IC}_{50}$ values higher than $10 \mu \mathrm{M}$ were considered as inactive. This was the case for 1 against HCT-116, A-549, and HL-60 cell lines. Only the melanoma cell line A-375 was weakly sensitive to 1 , exhibiting an $\mathrm{IC}_{50}$ of $6.1 \mu \mathrm{M}$. As can be seen from Table 3, among all tested compounds, derivatives $\mathbf{4 r}$ and $4 s$ exhibited the most potent cytotoxic activity against all four cell lines, with an increase of at least 1 order of magnitude compared to the parent compound $\mathbf{1}$.

The plasmatic stability of compound $4 \mathbf{s}$, one of the most potent of the series, was also investigated in comparison with the parent securinine $\mathbf{1}$ in order to anticipate further in vivo experiments. Results of these experiments are reported in Figure 2 and are expressed in percentage of remaining compound after 2 $\mathrm{h}$ incubation in mouse, rat, and human plasma. As can be seen from Figure 2, securinine $\mathbf{1}$ was found quite stable in by all tested plasma, while compound $4 \mathrm{~s}$ showed moderate to low plasma stability. Considering this unusual observation, further investigations were engaged in order to study this phenomena. More particularly, we selected three derivatives related to $4 \mathrm{~s}$ : (a) compound 4o, lacking the dimethylamino group, (b) compound $4 \mathbf{r}$, bearing a methoxy instead of the dimethylamino group, and (c) compound 3e, lacking the acetylenic link.

Compounds including the acetylenic linker $4 \mathbf{r}$ and particularly 4o were found unstable approximately at the same level, whereas 3e remained unchanged (Figure 2). One can conclude from these experiments that the acetylenic moiety combined with the conjugated double bonds of securinine is responsible for the plasmatic instability. Moreover, microsomal stability studies indicated the weak metabolic properties of the two series since no starting material was recovered after $1 \mathrm{~h}$ incubation with rat, mouse, and human microsomes (see SI). Taking into account the overall lack of stability, derivatives of the Sonogashira series would deserve further chemical optimization to engage in vivo experiments. Such efforts have been recently reported in the course of antifolate compounds research, for which the alkyne linkage was chemically stable. ${ }^{21}$

In conclusion, we reported the efficient synthesis of novel and diverse derivatives of securinine alkaloid $\mathbf{1}$. Compounds obtained by Suzuki coupling bearing an aryl moiety in $\mathrm{C}_{14}$ position could be considered inactive on colon cancer cell line HCT-116. 
However, it was found that the introduction of an acetylenic linker at the $\mathrm{C}_{14}$ position through Sonogashira coupling ${ }^{22}$ led to an increase in terms of potency against the same cancer cell line. In particular, compounds $\mathbf{4 s}$ and $\mathbf{4 r}$ were found to be highly cytotoxic on a panel of four tumoral cell lines. ${ }^{23}$

Based on these encouraging results, further studies are ongoing in order to synthesize a selected series of securinine derivatives with the aim of establishing detailed structureactivity relationships. ${ }^{24,25}$ Chemistry efforts are also engaged in order to obtain molecules exhibiting improved metabolic stability. Finally further pharmacological investigations are in progress to determine the mechanism of action of these compounds and possibly to identify the biological targets that are responsible for their potent cytotoxic properties. These results will be reported in due course.

\section{ASSOCIATED CONTENT}

\section{S Supporting Information}

The Supporting Information is available free of charge on the ACS Publications website at DOI: 10.1021/acsmedchemlett.5b00441.

Synthetic procedures, characterization data for key compounds $4 h, 4 q, 4 r, 4 s, 4 v$, and $4 w$, and biological assay methods (PDF)

\section{AUTHOR INFORMATION}

\section{Corresponding Authors}

*E-mail: fahy.jacques@orange.fr.

*E-mail: virginie.vidal@chimie-paristech.fr.

\section{Funding}

M. P. is grateful to IRPF and CNRS for funding.

Notes

The authors declare no competing financial interest.

\section{ACKNOWLEDGMENTS}

The following are gratefully acknowledged: Dr. Paola Arimondo and Dr. Isabelle Vandenberghe for helpful discussions, Viviane Brel and Céline Robichon for cellular pharmacology tests, and Antoine Dumoulin and Valérie Faucillon for metabolic stability studies.

\section{REFERENCES}

(1) Murav'eva, V. I.; Ban'Kovskii, A. I. Chemical study of alkaloids of Securinega suffruticosa. Dokl. Akda. Nauk. SSSR. 1956, 110, 998-1000.

(2) Buravtseva, G. R. Result of application of securinine in acute poliomyelitis. Farmakol. Toksikol. 1958, 21, 7-12.

(3) Raj, D.; Luczkiewicz, M. Securinega suffruticosa. Fitoterapia 2008, 79, 419-427.

(4) Copperman, R.; Copperman, G.; Der Marderosian, A. From Asia securinine-a central nervous stimulant is used in treatment of amytrophic lateral sclerosis. Pa. Med. 1973, 76, 36-41.

(5) Copperman, R.; Copperman, G.; Marderosian, A. D. Letter: Securinine. J. Am. Med. Assoc. 1974, 228, 288.

(6) Beutler, J. A.; Karbon, E. W.; Brubaker, A. N.; Malik, R.; Curtis, D. R.; Enna, S. J. Securinine Alkaloids: A new class of GABA receptor antagonist. Brain Res. 1985, 330, 135-140.

(7) Rognan, D.; Boulanger, T.; Hoffmann, R.; Vercauteren, D. P.; Andre, J.-M.; Durant, F.; Wermuth, C.-G. Structure and molecular modeling of $\mathrm{GABA}_{\mathrm{A}}$ receptor antagonists. J. Med. Chem. 1992, 35, 1969-1977.

(8) Tatematsu, H.; Mori, M.; Yang, T.-H.; Chang, J.-J.; Lee, T. T.-Y.; Lee, $\mathrm{K}$.-H. Cytotoxic principles of Securinega virosa: virosecurinine and viroallosecurinine and related derivatives. J. Pharm. Sci. 1991, 80, 325327.

(9) Li, M.; Han, S.; Zhang, G.; Wang, Y.; Ji, Z. Antiproliferative activity and apoptosis-inducing mechanism of l-securinine on human breast cancer MCF-7 cells. Pharmazie 2014, 69, 217-223.

(10) Rana, S.; Gupta, K.; Gomez, J.; Matsuyama, S.; Chakrabarti, A.; Agarwal, M. L.; Agarwal, A.; Agarwal, M. K.; Wald, D. N. Securinine induces p73-dependent apoptosis preferentially in p53-deficient colon cancer cells. FASEB J. 2010, 24, 2126-2134.

(11) Gupta, K.; Chakrabarti, A.; Rana, S.; Ramdeo, R.; Roth, B. L.; Agarwal, M. L.; Tse, W.; Agarwal, M. K.; Wald, D. N. Securinine, a myeloid differentiation agent with therapeutic potential for AML. PLoS One 2011, 6, e21203.

(12) Dong, N. Z.; Gu, Z. L.; Chou, W. H.; Kwok, C. Y. Securinine induced apoptosis in human leukemia HL-60 cells. Zhongguo Yao Li ХueBao 1999, 20, 267-270.

(13) Wald, D. N. Myeloid differentiation inducing agents U.S. Pat. Appl. 20140018383, 2014.

(14) (a) Hoffstrom, B. G.; Kaplan, A.; Letso, R.; Schmid, R. S.; Turmel, G. J.; Lo, D. C.; Stockwell, B. R. Inhibitors of protein disulfide isomerase suppress apoptosis induced by misfolded proteins. Nat. Chem. Biol. 2010, 6, 900-906. (b) Kaplan, A.; Stockwell, B. Structural Elucidation of a Small Molecule Inhibitor of Protein Disulfide Isomerase. ACS Med. Chem. Lett. 2015, 6, 966-971.

(15) Xu, S.; Sankar, S.; Neamati, N. Protein disulfide isomerase: a promising target for cancer therapy. Drug Discovery Today 2014, 19, 222-240.

(16) Li, J.-Y.; Zhao, B.-X.; Zhang, W.; Li, C.; Huang, X.-J.; Wang, Y.; Sun, P.-H.; Ye, W.-C.; Chen, W.-M. Unexpected ring contraction and oxidation rearrangement reactions of securinine. Tetrahedron 2012, 68, 3972-3979.

(17) Felpin, F. X. Practical and Efficient Suzuki-Miyaura CrossCoupling of 2-Iodocycloenones with Arylboronic Acids Catalyzed by Recyclable Pd(0)/C. J. Org. Chem. 2005, 70, 8575-8578.

(18) Chinchilla, R.; Nájera, C. The Sonogashira Reaction: A Booming Methodology in Synthetic Organic Chemistry. Chem. Rev. 2007, 107, 874-922.

(19) Chinchilla, R; Nájera, C. Recent advances in Sonogashira reactions. Chem. Soc. Rev. 2011, 40, 5084-5121.

(20) Felpin, F.-X. Ten Years of Adventures with Pd/C Catalysts: From Reductive Processes to Coupling Reactions. Synlett 2014, 25, 10551067.

(21) Zhou, W.; Viswanathan, K.; Hill, D.; Anderson, A. C.; Wright, D. L. Acetylenic Linkers in Lead Compounds: A Study of the Stability of the Propargyl-Linked Antifolates. Drug Metab. Dispos. 2012, 40, 20022008.

(22) During the preparation of this letter, researchers at Invenio Therapeutics Inc. reported comparable results: Gundluru, M. K.; Agarwal, M.; Xia, Z.; Karan, G.; Wald, D. Small molecule securinine and norsecurinine analogs and their use in cancers inflammatory diseases and infection. World Pat. WO2015/051284, 2015 Ap.

(23) Fahy, J.; Maillos, P.; Vidal, V.; Ayad, T.; Perez, M. Securinine derivatives as anticancer agents. PCT 14306944.1, 2015.

(24) Perez, M.; Ayad, T.; Maillos, P.; Poughon, V.; Fahy, J.; Ratovelomanana-Vidal, V. Eur. J. Med. Chem. 2016, 109, 287-293.

(25) Perez, M.; Ayad, T.; Maillos, P.; Poughon, V.; Fahy, J.; Ratovelomanana-Vidal, V. Highly Diastereoselective 1,6-Conjugate Addition of Arylboronic Acids to Securinine. Synlett 2016, DOI: $10.1055 / \mathrm{s}-0035-1561340$. 